\title{
Effects of the Nitric Oxide Synthase Inhibitor L-NAME on Recognition and Spatial Memory Deficits Produced by Different NMDA Receptor Antagonists in the Rat
}

\author{
Antonios Boultadakis' and Nikolaos Pitsikas*,' \\ 'Department of Pharmacology, School of Medicine, University of Thessaly, Larissa, Greece
}

\begin{abstract}
There is consistent experimental evidence that noncompetitive antagonists of the $N$-methyl-D-aspartate (NMDA) receptor, such as ketamine, MK-80I, and phencyclidine (PCP), impair cognition and produce psychotomimetic effects in rodents. Nitric oxide (NO) is considered as an intracellular messenger in the brain. The implication of $\mathrm{NO}$ in learning and memory is well documented. This study was designed to investigate the ability of the $\mathrm{NO}$ synthase inhibitor L-NAME to antagonize recognition and spatial memory deficits produced by the NMDA receptor antagonists, MK-80 I and ketamine, in the rat. L-NAME (I-3 mg/kg) counteracted MK-80 I- $(0.1 \mathrm{mg} / \mathrm{kg})$ and ketamine $(3 \mathrm{mg} / \mathrm{kg})$-induced performance impairments in the novel object recognition task. L-NAME $(10 \mathrm{mg} / \mathrm{kg})$ attenuated ketamine ( $15 \mathrm{mg} / \mathrm{kg}$ )-induced spatial working memory and retention deficits in the radial water maze paradigm. L-NAME, applied at $3 \mathrm{mg} / \mathrm{kg}$, however, disrupted rodents' performance in this spatial memory task. The present findings indicate ( $\mathrm{I}$ ) that L-NAME is sensitive to glutamate hypofunction produced by other than PCP NMDA antagonists such as MK-80I and ketamine and (2) that L-NAME alone differentially affects rodents' spatial memory.

Neuropsychopharmacology (20I0) 35, 2357-2366; doi:I0.1038/npp.2010.109; published online 21 July 2010
\end{abstract}

Keywords: L-NAME; MK-80I; ketamine; recognition memory; spatial memory; rat

\section{INTRODUCTION}

Schizophrenia is a serious mental disorder that affects up to $1 \%$ of the population worldwide. Cognitive deficits in schizophrenic patients are core features of the illness, and predict vocational and social disabilities for patients (Freedman, 2003). Numerous studies have indicated that the function of the glutamatergic system, in particular $\mathrm{N}$-methyl-D-aspartate (NMDA) receptors, might be compromised in schizophrenia. Exposure to noncompetitive NMDA receptor antagonists like phencyclidine (PCP) or ketamine produces behavioral symptoms that resemble both positive and negative symptoms of schizophrenia in healthy individuals (Javitt and Zukin, 1991; Krystal et al, 1994) and exacerbates symptoms in schizophrenic patients (Malhotra et al, 1997; Lahti et al, 2001). In addition, ketamine, PCP, or MK-801 induce schizophrenialike symptoms, including cognitive deficits, in rodents (Tricklebank et al, 1989; Verma and Moghaddam, 1996;

*Correspondence: Dr N Pitsikas, Department of Pharmacology, School of Medicine, University of Thessaly, Biopolis, 41 I-10 Larissa, Greece, Tel: + 30 24I0 685535, Fax: + 302410 685552,

E-mail: npitsikas@med.uth.gr

Received 7 May 20I0; revised 25 June 20I0; accepted 25 June 2010 de Lima et al, 2005). Owing to these psychotomimetic properties, NMDA receptor antagonists are widely used as models of schizophrenia in animals (Geyer and Markou, 1994).

Nitric oxide (NO), a soluble, short-lived, and freely diffusible gas, is an important intracellular messenger in the brain (Garthwaite, 1991). Reportedly, NO is involved in the mechanisms of synaptic plasticity in the hippocampus (O'Dell et al, 1991; Haley et al, 1992) and is important in cognition (Prast and Philippu, 2001).

A plethora of experimental data indicates the implication of NO in schizophrenia (Bernstein et al, 2005). In this context, an abnormal distribution of nitrergic neurons in the frontal and temporal lobes of schizophrenic patients has been observed, which may reflect that the normal pattern of neuronal migration during development of the cerebral cortex may be affected in these patients (Akbarian et al, 1993). In addition, experimental evidence suggests that polymorphisms in the neuronal nitric oxide synthase ( $n N O S)$ gene are associated with schizophrenia and prefrontal cortex (PFC) function in schizophrenic patients (Reif et al, 2006). Contradictory results were reported however, concerning the levels of NO metabolites in the serum of schizophrenic patients. Either high (Taneli et al, 2004; Yilmaz et al, 2007) or low (Ramirez et al, 2004) concentrations of NO metabolites have been reported. 
Because both alterations in the synaptic organization of the brain (Roberts et al, 2005) and neurotransmitter deficits (Costa et al, 2004) are key features of schizophrenia, excess NO might contribute to disturbed neurocircuitry in this disease. Reportedly, exceeding NO concentrations are associated with neuronal damage (Dawson et al, 1991), mitochondrial dysfunction (Das et al, 1998), and impairment of the NMDA-receptor-mediated neurotransmission (Clinton et al, 2003). As a whole, these data suggest that reduced NOS activity in schizophrenia may be neuroprotective. Therefore, efforts are made to develop NOS inhibitors as possible therapeutic tools for schizophrenia (Bernstein et al, 2005).

A number of animal studies have shown that diverse NOS inhibitors antagonized PCP-induced psychotomimetic effects (Johansson et al, 1997; Klamer et al, 2001, 2004, 2005a, b). In this context, it has been proposed that NOS inhibition selectively amends the behavioral effects of PCP and not those of MK-801 (Klamer et al, 2005a). In addition, that application of the nonselective NOS inhibitor L-NAME counteracted PCPinduced acquisition deficits in a spatial learning task in the rat has also been reported (Wass et al, 2006a, b).

Under our experimental conditions, we have observed that L-NAME (1-3 mg/kg) antagonized delay-dependent deficits in the novel object recognition memory task in the rat (Boultadakis et al, 2010). At the moment, it is not clear if and how L-NAME is able to counteract recognition memory deficits produced by NMDA hypofunction. In this context, we have observed that two NMDA receptor blockers with different profile in terms of potency or pharmacokinetic properties, MK-801 and ketamine, disrupted animals' performance in the novel object recognition paradigm (Pitsikas et al, 2006, 2008).

Taken the above evidences into account, the first aim of our study was to evaluate the efficacy of L-NAME in antagonizing MK-801- and ketamine-induced performance deficits in a recognition memory task in the rat. For this purpose, the novel object recognition task was selected. This test is a nonrewarded paradigm based on the spontaneous exploratory behavior of rats (Ennaceur, 2010). Subsequently, the efficiency of L-NAME to counteract ketamineinduced detrimental effects on spatial memory was assessed by using a radial water maze task (Pitsikas et al, 2007).

\section{MATERIALS AND METHODS}

\section{Animals}

Different groups of male (3-month-old) Wistar rats (Hellenic Pasteur Institute, Athens, Greece), weighing 250$300 \mathrm{~g}$, were used in this study. The animals were housed in Makrolon cages $(47.5 \times 20.5 \times 27 \mathrm{~cm})$, three per cage, in a regulated environment $\left(21 \pm 1^{\circ} \mathrm{C}, 50-55 \%\right.$ relative humidity, $12: 12 \mathrm{~h}$ light/dark cycle, white lights on from 0700 to 1900 hours), with free access to food and water. Experiments were conducted in the room where only these animals where housed, and took place during the light cycle between 1000 and 1400 hours.

Procedures involving animals and their care were conducted in conformity with the international guidelines in compliance with national and international laws and policies (EEC Council Directive 86/609, JL 358, 1, 12
December 1987; NIH Guide for Care and Use of Laboratory Animals, NIH publication no. 85-23, 1985).

\section{Novel Object Recognition Test}

The test apparatus and procedure have been extensively described earlier (Boultadakis et al, 2010). Before testing, for 3 consecutive days, rats were allowed to explore the apparatus for $2 \mathrm{~min}$. Testing consisted of a session of two 2-min trials. During the 'sample' trial (T1), two identical samples (objects) were placed in two opposite corners of the apparatus in a random manner. A rat was placed in the middle of the apparatus and was left to explore these two identical objects. After $\mathrm{T} 1$, the rat was put back in its home cage and an intertrial interval (ITI) was given. Subsequently, the 'choice' trial (T2) was performed. During T2, a new object $(\mathrm{N})$ replaced one of the samples presented in $\mathrm{T} 1$, therefore, the rats were reexposed to two objects: the familiar $(\mathrm{F})$ and the new $(\mathrm{N})$.

The times spent by rats in exploring each object during $\mathrm{T} 1$ and $\mathrm{T} 2$ were recorded manually by using a stopwatch. From this measure a series of variables was then calculated: the total time spent in exploring the two identical objects in $\mathrm{T} 1$, and that spent in exploring the two objects, (F) and (N) in T2. The discrimination between $(\mathrm{F})$ and $(\mathrm{N})$ during $\mathrm{T} 2$ was measured by comparing the time spent in exploring the $(\mathrm{F})$ with that spent in exploring the $(\mathrm{N})$. As this time may be biased by differences in overall levels of exploration a discrimination index $(D)$ was then calculated; $D=N-$ $F / N+F . D$ is the discrimination ratio and represents the difference in exploration time expressed as a proportion of the total time spent exploring the two objects in T2 (Cavoy and Delacour, 1993). In addition, motor activity of each animal expressed as total number of steps during each trial was also recorded.

\section{Radial Water Maze Test}

Spatial reference and spatial working memories were studied using an eight-arm radial water maze procedure modified from Jarrard et al (1984) and Pitsikas and Algeri (1992). The test apparatus has been described before (Pitsikas et al, 2007).

Each trial involved placing the rat in the water, facing the wall, at the end of one of the seven unbaited arms (start positions). Each rat was allowed $90 \mathrm{~s}$ to escape onto the platform. If it failed to escape within this time, it was guided to the platform. When the rat found the escape platform it was allowed to stay there for $30 \mathrm{~s}$. Then the rat was placed again into the maze for its next trial, which used the same platform location (eg, channel 1) and a different starting position as the previous trial. This was repeated until the rat found the platform or $90 \mathrm{~s}$ had elapsed whichever occurred first. Each animal received a daily session of two trials for 4 consecutive days.

Choices of arms (defined by whole body entry) were recorded manually for each trial. The order of entry into the maze arms was recorded so that the total number of errors could be calculated. Errors were quantified in terms of reference and working memory incorrect errors (Jarrard et al, 1984). Reference memory errors were the number of first entries into a channel that had never contained a 
platform. Working memory incorrect errors were the number of repeated entries into an arm that had never contained a platform (repeated entries into a reference memory arm thus, reflecting the combined effects of failures of both working and reference memory) (Okaichi et al, 1989). These parameters were averaged for each daily block of trials and for each rat, whose daily performance was thus characterized.

On day 5 , the rats performed a single spatial probe trial (Gage et al, 1984). This trial consisted of removing the platform from the baited arm of the radial water maze and allowing the rat to swim for $60 \mathrm{~s}$ in search of it. The time spent in each of the eight channels of the pool was calculated as a percentage over $60 \mathrm{~s}$.

\section{Drugs}

L-NAME, ( + )-MK-801 maleate (Sigma, St Louis, MO, USA) and ketamine hydrochloride were dissolved in saline $(\mathrm{NaCl}$ $0.9 \%$ ) and administered intraperitoneally (i.p.) in a volume of $1 \mathrm{ml} / \mathrm{kg}$. Doses of L-NAME were chosen on the basis of a study in which they were effective against learning impairments and did not produce adverse side effects (Boultadakis et al, 2010). The doses of MK-801 (0.1 mg/kg) and ketamine $(3 \mathrm{mg} / \mathrm{kg})$ were selected based on previous findings in which they were found to impair rat performance in the novel object recognition task without producing side effects (Pitsikas et al, 2006, 2008). For the radial water maze test, the dose of ketamine $(15 \mathrm{mg} / \mathrm{kg})$ was chosen based on a previous report in which it was found to impair place learning in a water maze task (Wesierska et al, 1990). For all studies, control animals received isovolumetric amounts of the vehicle $(\mathrm{NaCl} 0.9 \%)$.

\section{Experimental Protocol}

Experiment 1: effects of $L-N A M E$ in antagonizing MK-801-induced performance deficits in the novel object recognition task. Rats were randomly divided into eight experimental groups (10 rats per group) as follows: vehicle + vehicle; vehicle + L-NAME $1 \mathrm{mg} / \mathrm{kg}$; vehicle + L-NAME $3 \mathrm{mg} /$ $\mathrm{kg}$; vehicle + L-NAME $10 \mathrm{mg} / \mathrm{kg}$; MK-801 $0.1 \mathrm{mg} / \mathrm{kg}$ + vehicle; MK-801 $0.1 \mathrm{mg} / \mathrm{kg}+\mathrm{L}-\mathrm{NAME} 1 \mathrm{mg} / \mathrm{kg} ; \mathrm{MK}-8010.1 \mathrm{mg} / \mathrm{kg}+$ L-NAME $3 \mathrm{mg} / \mathrm{kg}$; and MK-801 $0.1 \mathrm{mg} / \mathrm{kg}+\mathrm{L}-\mathrm{NAME} 10 \mathrm{mg} /$ $\mathrm{kg}$. To study the effects of compounds on post-training memory components (storage and/or retrieval), we administered compounds immediately after $\mathrm{T} 1$. It has been reported that treatment with MK-801 (0.1 mg/kg) induces hypermotility (Verma and Moghaddam, 1996; Homayoun et al, 2004) and produce a sustained increase in stereotypy that peaked $40 \mathrm{~min}$ after injection and returned to baseline $2 \mathrm{~h}$ later (Homayoun et al, 2004). Therefore, it is quite possible that these factors may interfere with learning performance. There is also experimental evidence that recognition memory abilities in the young rat remained intact when a delay condition up to $6 \mathrm{~h}$ was used (Bartolini et al, 1996). To avoid the possibility that rats' performance is influenced by these already mentioned side effects due to the treatment with MK-801, we selected the 3-h ITI.

Experiment 2: effects of $L-N A M E$ in antagonizing ketamine-induced performance deficits in the novel object recognition task. Rats were randomly divided into eight experimental groups (10 rats per group) as follows: vehicle + vehicle; vehicle + L-NAME $1 \mathrm{mg} / \mathrm{kg} ;$ vehicle + L-NAME $3 \mathrm{mg} / \mathrm{kg}$; vehicle + L-NAME $10 \mathrm{mg} / \mathrm{kg}$; ketamine $3 \mathrm{mg} / \mathrm{kg}+$ vehicle; ketamine $3 \mathrm{mg} / \mathrm{kg}+\mathrm{L}-\mathrm{NAME} 1 \mathrm{mg} / \mathrm{kg}$; ketamine $3 \mathrm{mg} / \mathrm{kg}+\mathrm{L}-\mathrm{NAME} 3 \mathrm{mg} / \mathrm{kg}$; and ketamine $3 \mathrm{mg} / \mathrm{kg}+$ L-NAME $10 \mathrm{mg} / \mathrm{kg}$. To study the effects of compounds on post-training memory components (storage and/or retrieval), we administered the compounds just after T1. For this study, the 1-h ITI was selected as at this delay condition recognition memory is still intact in the vehicle-treated rat (Bartolini et al, 1996) and impairments associated with treatment with ketamine (hypermotility, stereotypies, ataxia) (Verma and Moghaddam, 1996) were not observed (Pitsikas et al, 2008).

Radial water maze task. Preliminary results have shown that rats treated with L-NAME $3 \mathrm{mg} / \mathrm{kg}$ showed a lower performance regarding the vehicle-treated animals. Therefore, the effects exerted by $3 \mathrm{mg} / \mathrm{kg}$ L-NAME on rats' spatial memory and the ability of L-NAME to antagonize ketamineinduced performance deficits in the radial water maze were subsequently assessed in two separate studies.

Experiment 3: effects of L-NAME (3 mg/ $\mathrm{kg})$ on animals' performance in the radial water maze task. Rats were randomly divided into two experimental groups (10 rats per group) as follows: vehicle and L-NAME $3 \mathrm{mg} / \mathrm{kg}$. L-NAME and vehicle were injected every day $60 \mathrm{~min}$ before starting testing.

Experiment 4: effects of L-NAME in antagonizing ketamine-induced performance deficits in the radial water maze task. Animals were randomly divided into six experimental groups (10 rats per group) as follows: vehicle + vehicle; vehicle + L-NAME $1 \mathrm{mg} / \mathrm{kg}$; vehicle + L-NAME $10 \mathrm{mg} / \mathrm{kg}$; ketamine $15 \mathrm{mg} / \mathrm{kg}$ + vehicle; ketamine $15 \mathrm{mg} / \mathrm{kg}$ + L-NAME $1 \mathrm{mg} / \mathrm{kg}$; and ketamine $15 \mathrm{mg} / \mathrm{kg}+\mathrm{L}-\mathrm{NAME}$ $10 \mathrm{mg} / \mathrm{kg}$. Control rats were treated with the vehicle 60 and $40 \mathrm{~min}$ before starting the daily testing. Animals were treated with L-NAME and vehicle 60 and $40 \mathrm{~min}$, respectively, before starting testing. Rats received vehicle and ketamine 60 and $40 \mathrm{~min}$, respectively, before starting the daily testing. Rats received L-NAME and ketamine 60 and $40 \mathrm{~min}$, respectively, before starting the daily session. Ketamine administration $(10-30 \mathrm{mg} / \mathrm{kg})$ is associated with behavioral symptoms, such as hypermotilty and stereotypy, that reach the peak effect 15 min after treatment (Wesierska et al, 1990; Verma and Moghaddam, 1996). On the basis of these evidences, we performed the daily administration of ketamine 40 min before testing as at this condition ketamine does not induce side effects.

\section{Statistical Analysis}

Data are expressed as mean \pm SEM. In experiments 1 and 2, results were analyzed using the two-way analysis of variance (ANOVA). Post hoc comparisons were performed by the Tukey's $t$-test. In experiment 3 , reference and working memory incorrect errors were evaluated by the two-way ANOVA with a split-plot design (between-within subjects). Post hoc comparisons were performed by the Tukey's $t$-test. 
Spatial probe trial data are calculated as median and interquartile ranges. When comparing among groups the percentage of time spent in the previously reinforced arm, Wilcoxon's nonparametric test was used.

In experiment 4 , the effects of drugs on daily performance (reference and working memory) were analyzed by the three-way ANOVA (two between, one within subjects). Significant interactions between ketamine, L-NAME, and trials were further analyzed by comparing ketamine- and L-NAME-treated and -nontreated rats at each level separately for the 4-day periods, using the two-way ANOVA with a split-plot design. Post hoc comparisons were performed by the Tukey's $t$-test. Spatial probe data were analyzed by Kruskall-Wallis nonparametric test followed by the Newman-Keuls post hoc test. A p-value $<0.05$ was considered significant (Kirk, 1968).

\section{RESULTS}

Experiment 1: Effects of L-NAME in Antagonizing MK-801-Induced Performance Deficits in the Novel Object Recognition Task

A two-way ANOVA of motor activity results showed a main effect either of MK-801 $(\mathrm{F}(1,72)=18.4, p<0.01)$ or of L-NAME $(\mathrm{F}(3,72)=2.93, p<0.05)$ indicating that rats that received both these compounds showed higher motility levels as compared to the other groups (Table 1). Total exploration levels were not different among the various experimental groups (Table 1).

Data for index $D$ (Figure 1) revealed a significant main effect of MK-801 $(\mathrm{F}(1,72)=24.2, p<0.01)$, of L-NAME $(\mathrm{F}(3,72)=4.8, \quad p<0.01)$ and a significant $\mathrm{MK}-801 \times \mathrm{L}-$ NAME interaction $(\mathrm{F}(3,72)=3.8, p=0.014)$. Post hoc comparisons have shown that rats treated with the vehicle + MK-801 and the MK-801 + L-NAME $10 \mathrm{mg} / \mathrm{kg}$ were unable to discriminate between the familiar and the novel object as compared to the rest of groups $(p<0.05)$.

\section{Experiment 2: Effects of L-NAME in Antagonizing Ketamine-Induced Performance Deficits in the Novel Object Recognition Task}

A two-way ANOVA of motility results showed only a significant main effect of ketamine $(\mathrm{F}(1,72)=29.8, p<0.01)$, suggesting that animals treated with ketamine showed higher locomotor activity levels than the other experimental groups (Table 2). Total exploration levels were not different among the various experimental groups (Table 2).

Concerning $D$ data, a significant main effect of ketamine $(\mathrm{F}(1,72)=15.8, \quad p<0.01), \quad$ of $\quad$ L-NAME $\quad(\mathrm{F}(3,72)=3.4$, $p<0.05)$ and a significant interaction between ketamine and L-NAME $(\mathrm{F}(3,72)=3, p<0.05)$ was evidenced. Post hoc analysis has shown that animals treated with the vehicle + ketamine and the ketamine + L-NAME $10 \mathrm{mg} / \mathrm{kg}$ were unable to discriminate between the familiar and the novel object as compared with the other groups $(p<0.05$, Figure 2).

\section{Experiment 3: Effects of L-NAME (3 mg/kg) on Animals' Performance in the Radial Water Maze Task}

Reference memory. Data are presented in Figure 3a. An overall ANOVA showed that both the vehicle- and the L-NAME-treated animals made progressively fewer reference memory errors over days $(\mathrm{F}(3,54)=5.47, p<0.01)$. In addition, the L-NAME $3 \mathrm{mg} / \mathrm{kg}$-treated animals committed significantly more reference memory errors than their vehicle-treated counterparts $(\mathrm{F}(1,18)=8.48, p<0.01)$.

Working memory. Results are illustrated in Figure $3 \mathrm{~b}$. Statistical analysis of the working memory data evidenced

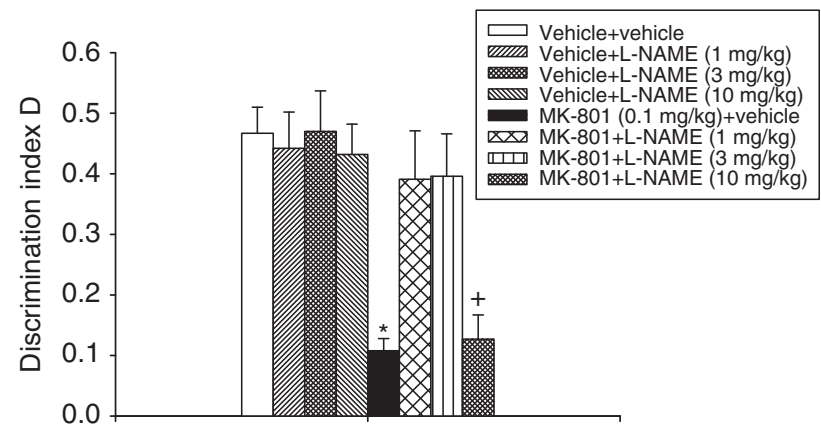

Figure I Novel object recognition task. Vehicle, MK-80I, and L-NAME were injected i.p., just after TI. The 3-h ITI was used. Results are expressed as mean $\pm \mathrm{SEM}$. Discrimination index $D$ performance expressed by different groups of rats during $\mathrm{T} 2$. ${ }^{*} p<0.05$ vs all the other groups (except the MK-80I + L-NAME I 0 mg/kg group); ${ }^{+} p<0.05$ vs all the other groups (except the MK-80I + vehicle group).

Table I Effects of MK-80I and L-NAME on Rats' Performance in the Novel Object Recognition Task

\begin{tabular}{|c|c|c|c|}
\hline Group & $N$ & $\begin{array}{c}\text { T2 motor activity (number of steps) } \\
\text { mean } \pm \text { SEM }\end{array}$ & $\begin{array}{c}\text { T2 exploration time (s) } \\
\text { mean } \pm \text { SEM }\end{array}$ \\
\hline Vehicle+vehicle & 10 & $47.5 \pm 1.8$ & $12.5 \pm 0.3$ \\
\hline Vehicle+L-NAME (3 mg/kg) & 10 & $35.5 \pm 2.1$ & $11.6 \pm 1.3$ \\
\hline Vehicle+L-NAME (10 mg/kg) & 10 & $44.4 \pm 3.9$ & $12.5 \pm 0.6$ \\
\hline MK-80 I +L-NAME (3 mg/kg) & 10 & $47.2 \pm 5.1$ & $12.4 \pm 0.9$ \\
\hline MK-80 I +L-NAME (I 0 mg/kg) & 10 & $54.1 \pm 3.6$ & $12.4 \pm 0.4$ \\
\hline
\end{tabular}


Table 2 Effects of Ketamine and L-NAME on Rats' Performance in the Novel Object Recognition Task



Abbreviation: $\mathrm{N}$, number of rats.

Compounds were injected intraperitoneally immediately after TI.



Figure 2 Novel object recognition task. Vehicle, ketamine, and L-NAME were injected i.p., just after TI. The I-h ITI was used. Results are expressed as mean \pm SEM. Discrimination index $D$ performance expressed by different groups of rats during T2. $* p<0.05$ vs all the other groups (except the ketamine + L-NAME $10 \mathrm{mg} / \mathrm{kg}$ group); ${ }^{+} p<0.05$ vs all the other groups (except the ketamine + vehicle group).

that either the vehicle- or the L-NAME-treated animals made progressively fewer working memory incorrect errors over days $(\mathrm{F}(3,54)=9.87, p<0.01)$. Moreover, the $\mathrm{L}-\mathrm{NAME}$ $3 \mathrm{mg} / \mathrm{kg}$-treated rats made a significantly higher number of working memory incorrect errors than their vehicle-treated cohorts $(\mathrm{F}(1,18)=4.4, p=0.05)$.

Spatial probe trial. Probe analysis comparing percentage of time spent in the previously reinforced quadrant showed an effect of treatment. The $3 \mathrm{mg} / \mathrm{kg}$ L-NAME group spent significantly less time in the previously baited channel than the control group $(p<0.05$, Figure $3 c)$.

\section{Experiment 4: Effects of L-NAME in Antagonizing Ketamine-Induced Performance Deficits in the Radial Water Maze Task}

Reference memory. Data are presented in Figure 4a. Overall ANOVA did not show a significant three-way ketamine $x$ L-NAME $\times$ days interaction, neither a significant two-way interaction between ketamine and L-NAME, between ketamine and days, and between L-NAME and days. A significant main effect of ketamine $(\mathrm{F}(1,216)=25.1$, $p<0.01)$, of days $(\mathrm{F}(3,216)=11.1, p<0.01)$ but not of L-NAME however was revealed.
Additional analyses of rats' performance in this spatial reference memory task were carried out by splitplot ANOVAs. The ketamine + vehicle-treated animals committed significantly more reference memory errors than their vehicle + vehicle-treated cohorts $(\mathrm{F}(1,18)=40.6$, $p<0.01)$. L-NAME, at any dose, failed to counteract this ketamine-induced reference memory impairment.

Animals treated with $1 \mathrm{mg} / \mathrm{kg}$ L-NAME + ketamine made more reference memory errors than the vehicle + L-NAME $1 \mathrm{mg} / \mathrm{kg}$-treated rats $(\mathrm{F}(1,18)=7.3, p=0.014)$. Choice accuracy abilities, in terms of number of reference memory errors, of the $10 \mathrm{mg} / \mathrm{kg}$ L-NAME + ketamine-treated rats and those animals that received vehicle + L-NAME $10 \mathrm{mg} / \mathrm{kg}$ were not different.

Working memory. Results are presented in Figure $4 \mathrm{~b}$. Overall ANOVA did not show a significant three-way ketamine $\times$ L-NAME $\times$ days interaction, neither a significant two-way interaction between ketamine and days and between L-NAME and days. Interestingly, a significant twoway interaction between ketamine and L-NAME was evidenced $(F(2,216)=3.64, p<0.05)$ indicating that the rates of learning were different among the various groups. In addition, a significant main effect of ketamine $(\mathrm{F}(1,216)=28.1, p<0.01)$, of days $(\mathrm{F}(3,216)=8, p<0.01)$ but not of L-NAME was evidenced.

Further analyses of performance of the animal in this spatial working memory paradigm were carried out by splitplot ANOVAs. Animals that received ketamine + vehicle committed significantly more working memory incorrect errors than their vehicle + vehicle counterparts $(\mathrm{F}(1,18)=$ $17.9, p<0.01)$. Rats that received $10 \mathrm{mg} / \mathrm{kg}$ L-NAME + ketamine made significantly fewer working memory incorrect errors than their counterparts treated with ketamine + vehicle $(\mathrm{F}(1,18)=8.35, p<0.01) \mathrm{AQ}$. In addition, these rats performance, in terms of working memory incorrect errors, was not different than that showed by their vehicle cohorts $(10 \mathrm{mg} / \mathrm{kg}$ $\mathrm{L}-\mathrm{NAME}$ + vehicle-treated rats). Animals treated with $1 \mathrm{mg} / \mathrm{kg}$ L-NAME + ketamine made a higher number of working memory incorrect errors than the vehicle + L-NAME $1 \mathrm{mg} / \mathrm{kg}$ treated rats $(\mathrm{F}(1,18)=13.8, p<0.01)$.

Spatial probe trial. Probe analysis comparing percentage of time spent in the previously reinforced quadrant showed an effect of treatment $(H=25.8, p<0.01$, Figure $4 \mathrm{c})$. Animals 


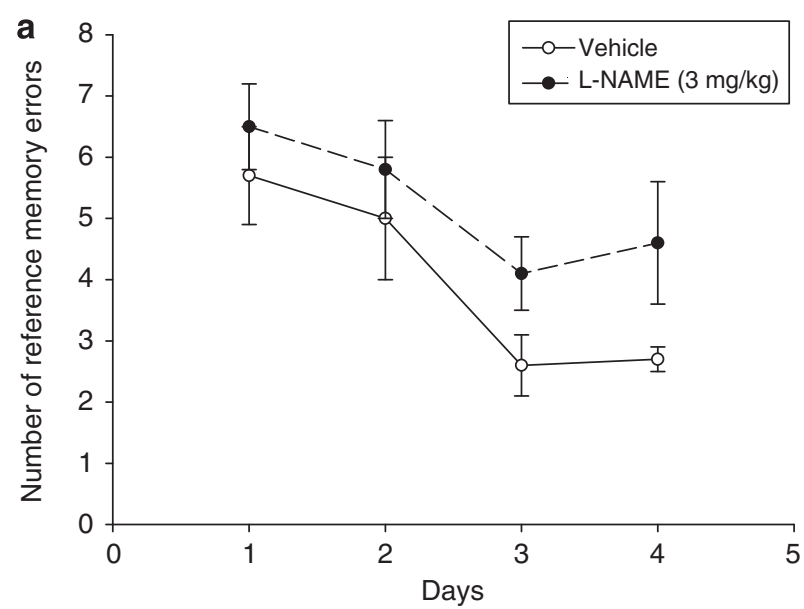

attenuated this ketamine-induced impairment $(p<0.05$ vs ketamine + vehicle-treated animals).

\section{DISCUSSION}

The major findings of this study have shown that the NMDA receptor antagonists $\mathrm{MK}-801$ and ketamine induced performance deficits in different cognitive tasks in the rat. These cognitive impairments could be antagonized by the NOS inhibitor L-NAME.

\section{Novel Object Recognition Task}

Our study results are in line with previous studies in which post-training administration of both MK-801 and ketamine disrupted rats' performance in the novel object recognition task (Pitsikas et al, 2006, 2008). A single post-training injection of L-NAME ( 1 and 3 , but not $10 \mathrm{mg} / \mathrm{kg}$ ) attenuated either the MK-801- or the ketamine-induced performance deficits in this recognition memory paradigm. MK-801, ketamine and L-NAME influenced rats' performance during retention, seemingly reflecting a modulation of posttraining mnemonic processes (storage and/or retrieval of information).

Compounds were administered systemically, thus, it cannot be excluded that nonspecific factors (attentional, sensorimotor deficits) might have influenced animals' performance. All animals that received these two NMDA receptor antagonists showed higher levels of motility, but not of general exploration during T2, regarding their control cohorts. Treatment with L-NAME did not antagonize this NMDA blockade-induced hyperactivity but successfully counteracted recognition memory deficits. This pattern of results implies that the effects of the compounds on rats' cognitive performance were unrelated to the extent of motility and exploratory behavior.

Present results are in agreement with our previous findings showing that L-NAME did not impair recognition memory but it reversed delay-dependent impairments in the novel object recognition task, especially at lower doses (Boultadakis et al, 2010).

\section{Radial Water Maze Task}

Data have shown that L-NAME (1 and $10 \mathrm{mg} / \mathrm{kg}$ ) alone did not disrupt animals' spatial learning abilities. A per se effect of L-NAME was observed when this NOS inhibitor was delivered at the dose of $3 \mathrm{mg} / \mathrm{kg}$, however. Those animals' spatial learning abilities were poorer as compared to those shown by the vehicle + vehicle-treated subjects. Rats that received ketamine performed less efficiently than the vehicle + vehicle and the L-NAME (1 and $10 \mathrm{mg} / \mathrm{kg})+$ vehicle-treated rats suggesting that this NMDA receptor antagonist disrupted both spatial reference and spatial working memory. The higher dose of L-NAME $(10 \mathrm{mg} / \mathrm{kg})$ attenuated ketamine-induced working, but not reference, memory deficits. Both ketamine + L-NAME groups expressed a lower performance as compared to the respective cohorts treated with L-NAME + vehicle.

When the ability of rats to use the extramaze cues surrounding the radial water maze was evaluated (spatial probe trial) all control rats persistently swam more in the 
previously reinforced arm of the maze, whereas L-NAME $3 \mathrm{mg} / \mathrm{kg}$ + vehicle, ketamine + vehicle, and ketamine + L-NAME $1 \mathrm{mg} / \mathrm{kg}$-treated animals were unable to do so.
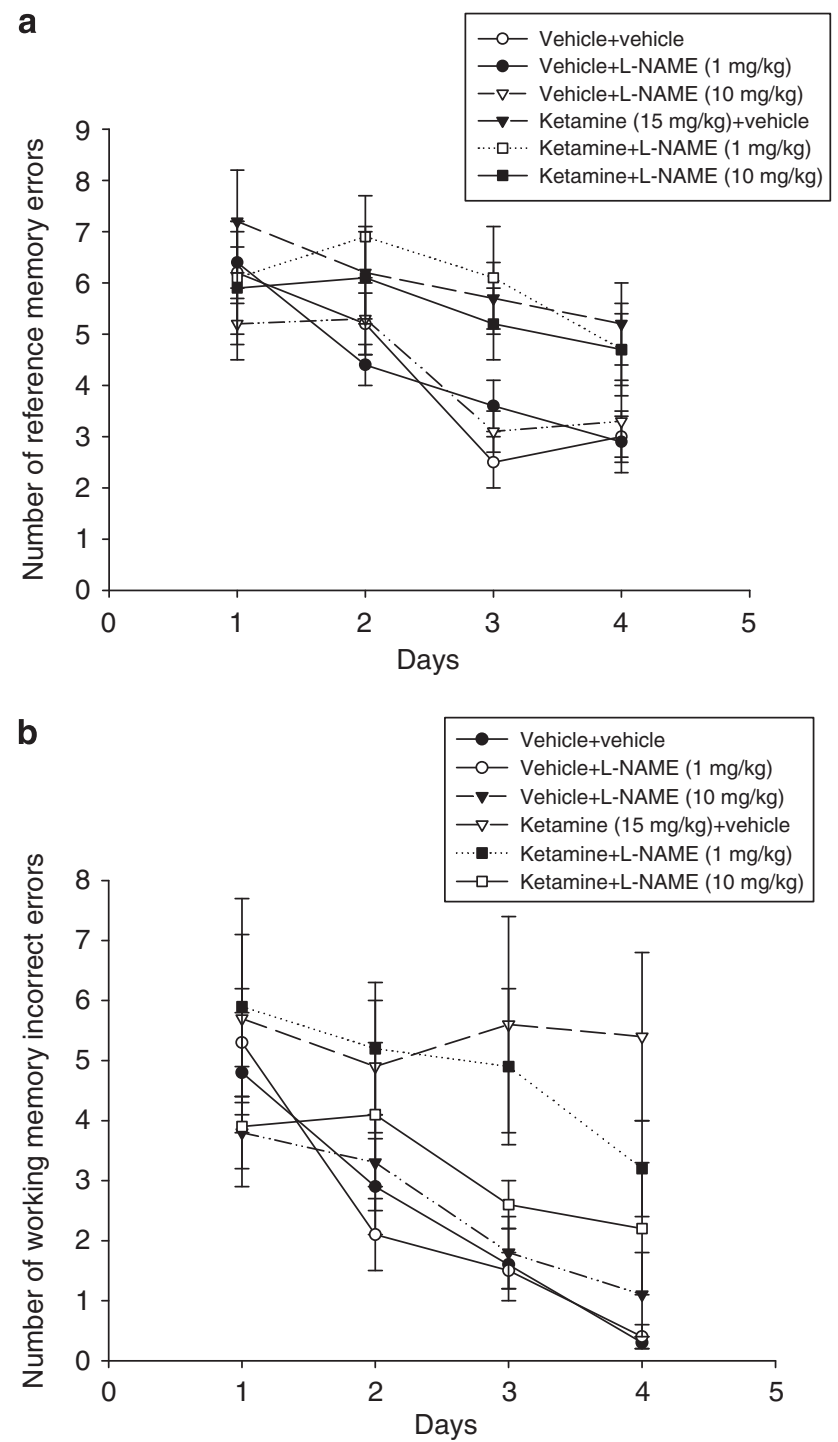

C

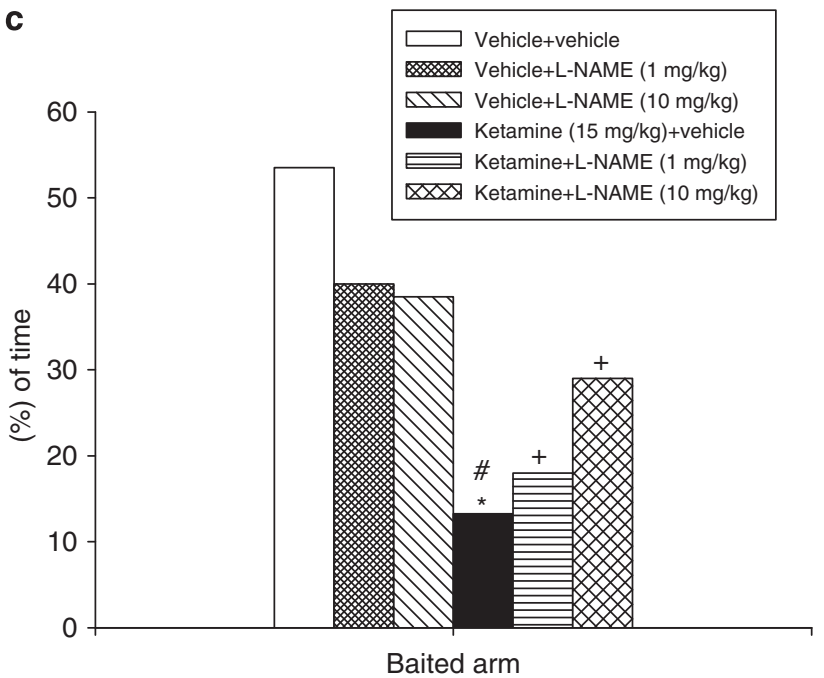

L-NAME $(10 \mathrm{mg} / \mathrm{kg})$ attenuated this ketamine-produced disrupting effect.

The radial water maze test evaluates rodents' spatial memory. The procedure used in this study offers the possibility to assess in the same animal simultaneously two aspects of memory (reference and working; Jarrard et al, 1984; Pitsikas and Algeri, 1992). This within-subject and within-task design is advantageous because each dissociation is obtained from the same animal at the same time, minimizing many sources of variability such as task magnitude of reinforcement, motivational, perceptual, and motor processes (Olton, 1983).

Our results of the radial water maze paradigm are consistent with previous reports in which the effects of L-NAME $(10 \mathrm{mg} / \mathrm{kg})$ on glutamatergic hypofunction were assessed (Wass et al, 2006b, a). The outcome of these studies was that treatment with this NOS inhibitor antagonized PCP-induced spatial reference, spatial working memory, but not retention deficits in a modified Morris water maze procedure (Wass et al, 2006b, a).

A potential issue when using NOS inhibitors relates to its hypertensive properties. It is difficult, therefore, to quantify how and at what extent these cardiovascular effects might have specifically affected animals' cognitive performance. Reportedly, NOS inhibitors injected peripherally induce a nearly maximal hypertensive effect at $10 \mathrm{mg} / \mathrm{kg}$ (Rees et al, 1990). Under our experimental conditions, L-NAME, administered systemically at $10 \mathrm{mg} / \mathrm{kg}$, attenuated ketamineinduced performance deficits in the radial water maze task. This implies that the effects of this compound on rats' cognitive performance were unrelated to its potential hypertensive action.

\section{NMDA Hypofunction and Nitric Oxide}

Pharmacological blockade of NMDA receptors has been proposed as a relevant model of schizophrenia in humans and animals. (Javitt and Zukin, 1991; Geyer and Markou, 1994; Krystal et al, 1994). The NMDA antagonist treatment model has excellent face validity for cognitive symptoms of schizophrenia because an exposure to these drugs impairs PFC-dependent cognitive functions in a manner similar to schizophrenia (Javitt and Zukin, 1991; Krystal et al, 1994). PCP, ketamine, and MK- 801 produce their psychotomimetic effects by blocking NMDA receptors located on GABA interneurons, resulting in decreased firing of GABAergic inhibitory neurons and, thereby, increased excitability in limbic circuits (Olney et al, 1991; Moghaddam et al, 1997). This disinhibitory action elicits an increase in terms of neuronal activity and excessive glutamate and dopamine

Figure 4 Radial water maze task. Vehicle, ketamine, and L-NAME were injected i.p., every day 40 and 60 min, respectively, before testing. (a) Spatial reference memory. Results are expressed as mean \pm SEM. Number of errors cumulating over days by different groups of rats. (b) Spatial working memory. Results are expressed as mean \pm SEM. Number of errors cumulating over days by different groups of rats. (c) Percentage of total time spent in the previously reinforced arm of the radial water maze by different groups of rats. Results are expressed as medians. ${ }^{*} p<0.05$ vs the vehicle + vehicle-treated animals; ${ }^{+} p<0.05$ vs the respective control populations; ${ }^{*} p<0.05$ vs ketamine + L-NAME 10 mg $/ \mathrm{kg}$-treated rats. 
release in the PFC and limbic regions (Moghaddam et al, 1997; Lorrain et al, 2003; Razoux et al, 2007).

NOS inhibitors may exert both excitatory and inhibitory effects on NMDA-receptor-associated events. The dual action of NO as mediator and negative modulator of glutamate neurotransmission at the NMDA receptor complex gives this system a unique role in regulating the balance of excitatory and inhibitory influences. It is this balance of excitatory and inhibitory processes that is likely to be disrupted in schizophrenia, as proposed by the glutamatergic hypofunction (Dawson et al, 1991).

Our findings indicate that L-NAME, for the first time to our knowledge, antagonized both MK-801- and ketamineinduced recognition memory deficits, suggesting that this NOS inhibitor is also effective against NMDA blockade produced by the action of NMDA antagonists other than PCP. Furthermore, L-NAME was found to attenuate spatial memory deficits produced by ketamine in the rat. The latter, support and extend previous results in which spatial memory deficits induced by another NMDA antagonist (PCP) were counteracted by this NOS inhibitor (Wass et al, 2006b, a). Collectively, the present results further suggest an involvement of NO in the NMDA hypofunction-induced cognitive deficits.

Contrary to the expectations, when L-NAME was administered alone at $3 \mathrm{mg} / \mathrm{kg}$, it impaired rats' spatial but not recognition memory abilities. It remains uncertain if this dual effect of L-NAME on memory was related to the task specificity, the type of memory studied, and/or the different pharmacological design used.

The radial water maze is a negatively reinforced paradigm assessing spatial memory. The novel object recognition test is a task that does not involve at all the learning of a rule as it is based on the spontaneous exploratory behavior of rodents evaluating recognition memory (Ennaceur, 2010). In the novel object recognition task rats received a single injection of compounds just after the 'sample' trial T1. Conversely, in the radial water maze paradigm, treatment was applied once per day $60 \mathrm{~min}$ before starting the daily testing, for 5 consecutive days.

Interestingly, this impairing effect of L-NAME on spatial memory, was not observed at the 'side' doses of 1 and $10 \mathrm{mg} / \mathrm{kg}$ revealing thus, an U-shaped dose-effect curve. At present, the biological bases of U-shaped dose-response relationship are unknown, although receptor fatigue or tachyphylaxis (Day, 1979) has been suggested as potential mechanisms (Martinez, 1986). Moreover, L-NAME has also been reported to function as a partial agonist in the NO system, antagonizing or stimulating NO synthesis in different tissues (Archer and Hampi, 1992). Further studies are needed however to clarify this important issue.

The mechanism(s) of action of low doses of NOS inhibitors on learning and memory is not yet clarified and is matter of investigation. It has been shown that the neuroprotective effects of NOS inhibitors were obtained when inhibition of NO production was only mild and transient. Conversely, long-lasting inhibition of NO production by high doses of NOS inhibitors leads to neurotoxicity (Contestabile et al, 2003). Small changes in local NO concentration, and the time of administration therefore, may be a key factor in determining its biological action (Contestabile et al, 2003).
It has been reported that a wide range of translational PCP-induced effects including deficits in preattentive information processing, nonassociative learning, selective attention, spatial memory can all be prevented by interfering with the production of NO (Johansson et al, 1997; Klamer et al, 2001, 2004, 2005a, b). These findings suggest that the schizophrenia-like behavioral effects of PCP in rodents are, at least in part, mediated by an increase in NO activity (Palsson et al, 2009). This is supported by a recent study showing an NO-dependent increase in cyclic GMP (cGMP) signaling, a main effector of NO in the brain, in the mouse PFC following PCP administration (Fejgin et al, 2008). In this context, it has been found that L-NAME attenuated sensorimotor gating deficits caused by PCP, by reducing PCP-induced increase in CGMP production in the PFC of the mouse brain (Fejgin et al, 2008). This mechanism might be a plausible explanation for the beneficial effects of low doses of L-NAME on memory impairments related to glutamatergic hypofunction. Further studies however are required to elucidate this important issue.

\section{Concluding Remarks}

In summary, studies presented herein show that L-NAME was capable in antagonizing MK-801 and ketamine-induced memory deficits and this beneficial action exerted by L-NAME on cognition was observed at a different dose range. This, in turn, indicates that L-NAME is sensitive to glutamatergic hypofunction produced by other than PCP NMDA receptor antagonists such as MK-801 and ketamine. In addition, the present results show that L-NAME alone differentially affects rodents' spatial memory. The latter suggest a careful consideration of the balance between neurodegenerative and neuroprotective effects produced by this NOS inhibitor as L-NAME might constitute a potential candidate for the treatment of schizophrenia.

\section{ACKNOWLEDGEMENTS}

This study was supported by a grant of the Research Committee of the University of Thessaly (no. 3689) to NP.

\section{DISCLOSURE}

The authors hereby declare that no financial support or compensation has been received from any individual or corporate entity over the past 3 years for research or professional service and there are no personal financial holdings that could be perceived as constituting a potential conflict of interest.

\section{REFERENCES}

Akbarian S, Bunney WE, Potkin SG, Wigal SB, Hagman JO, Sandman CA et al (1993). Altered distribution of nicotinamideadenine dinucleotide phosphate-diaphorase cells in frontal lobe of schizophrenics implies disturbances of cortical development. Arch Gen Psychiatry 50: 169-177.

Archer SL, Hampi V (1992). NG-mono-methyl-L-arginine causes nitric oxide synthesis in isolated arterial rings: trouble in paradise. Biochem Biophysic Res Commun 188: 590-596. 
Bartolini L, Casamenti F, Pepeu G (1996). Aniracetam restores object recognition impaired by age, scopolamine and nucleus basalis lesions. Pharmacol Biochem Behav 53: 277-283.

Bernstein HG, Bogerts B, Keilhoff G (2005). The many faces of nitric oxide in schizophrenia. A review. Schizophr Res 78: $69-86$.

Boultadakis A, Georgiadou G, Pitsikas N (2010). Effects of the nitric oxide synthase inhibitor L-NAME on different memory components as assessed in the object recognition task in the rat. Behav Brain Res 207: 208-214.

Cavoy A, Delacour J (1993). Spatial but not object recognition is impaired by aging in rats. Physiol Behav 53: 527-530.

Contestabile A, Monti B, Contestabile A, Ciani E (2003). Brain nitric oxide and its dual effect in neuroprotection/neurodegeneration: understanding molecular mechanisms to devise drug approaches. Curr Med Chem 10: 1241-1253.

Costa E, Davis JM, Dong E, Grayson DR, Guidotti A, Tremolizzo L et al (2004). A GABAergic cortical deficit dominates schizophrenia pathophysiology. Crit Rev Neurobiol 16: 1-23.

Clinton SM, Haroutunian V, Davis KL, Meader-Woodraff JH (2003). Altered transcript expression of NMDA receptorassociated postsynaptic proteins in the thalamus of subjects with schizophrenia. Am J Psychiatry 160: 1100-1109.

Das I, Ramchand CN, Gliddon A, Hirsch SR (1998). Nitric oxide, free radicals and polyamines may have a role in membrane pathology of schizophrenia. Neuropsychobiology 37: 65-67.

Dawson VL, Dawson TM, London ED, Bredt DS, Snyder SH (1991). Nitric oxide mediates glutamate neurotoxicity in primary cortical cultures. Proc Natl Acad Sci USA 88: 6368-6371.

Day MD (1979). Autonomic Pharmacology. Experimental and Clinical Aspects. Churchill Livingston: New York.

de Lima MNM, Laranja DC, Bromberg E, Roesler R, Schroeder N (2005). Pre- or post-training administration of the NMDA receptor blocker MK-801 impairs object recognition memory in rats. Behav Brain Res 156: 139-143.

Ennaceur A (2010). One-trial object recognition in rats and mice: methodological and theoretical issues. Behav Brain Res print copy in press (originally published online 6 Jan 2010, at www.sciencedirect/bbr.2009.12.036).

Fejgin K, Palsson E, Wass C, Svensson L, Klamer D (2008). Nitric oxide signaling in the medial prefrontal cortex is involved in the biochemical and behavioral effects of phencyclidine. Neuropsychopharmacology 33: 1874-1883.

Freedman R (2003). Schizophrenia. N Engl J Med 349: 1738-1749.

Gage FH, Dunnett SB, Bjorklund A (1984). Spatial learning and motor deficits in aged rats. Neurobiol Aging 5: 43-48.

Garthwaite J (1991). Glutamate nitric oxide and cell-cell signalling in the nervous system. Trends Neurosci 14: 60-67.

Geyer MA, Markou A (1994). Animal models of psychiatric disorders. In: Bloom FE, DL Kupfer (eds). Psychopharmacology, The Fourth Generation of Progress. Raven Press: New York, pp 787-798.

Haley JE, Wilcox GL, Chapman PF (1992). The role of nitric oxide in hippocampal long-term potentiation. Neuron 8: 211-216.

Homayoun H, Stefani MR, Adams BW, Tamagan GD, Moghaddam B (2004). Functional interaction between NMDA and mGlu5 receptors: effects on working memory, instrumental learning, motor behaviors and dopamine release. Neuropsychopharmacology 29: 1259-1269.

Jarrard L, Okaichi H, Steward O, Goldschmidt R (1984). On the role of the hippocampal connections in the performance of place and cue tasks: comparisons with damage to hippocampus. Behav Neurosci 98: 946-954.

Javitt DC, Zukin SR (1991). Recent advances in the phencyclidine model of schizophrenia. Am J Psychiatry 148: 1301-1308.

Johansson C, Jackson DM, Svensson L (1997). Nitric oxide synthase inhibition blocks phencyclidine-induced behavioural effects on prepulse inhibition and locomotor activity in the rat. Psychopharmacology 131: 167-173.

Kirk RE (1968). Experimental Design: Procedures for the Behavioral Science. Brooks/Cole: Belmont, CA.

Klamer D, Engel JA, Svensson L (2001). The nitric oxide synthase inhibitor, L-NAME, block phencyclidine-induced disruption of prepulse inhibition in mice. Psychopharmacology 156: 182-186.

Klamer D, Engel JA, Svensson L (2004). The neuronal selective nitric oxide synthase inhibitor, Nomega-propyl-L-arginine, blocks the effects of phencyclidine on prepulse inhibition and locomotor activity in mice. Eur J Pharmacol 503: 103-107.

Klamer D, Palsson E, Wass C, Archer T, Engel JA, Svensson L (2005a). Selective interaction of nitric oxide synthase inhibition with phencyclidine: behavioural and NMDA receptor binding studies in the rat. Behav Brain Res 159: 95-103.

Klamer D, Palsson E, Wass C, Archer T, Engel JA, Svensson L (2005b). Antagonism of the nitric oxide synthase inhibitor L-NAME, of the effects of phencyclidine on latent inhibition in taste aversion conditioning. Behav Brain Res 161: 60-68.

Krystal JH, Karper LP, Seibyl JP, Freeman GK, Delaney R, Bremmer JD et al (1994). Sub-anesthetic effects of the noncompetitive NMDA antagonist, ketamine, in humans. Psychotomimetic, perceptual, cognitive and neuroendocrine responses. Arch Gen Psychiatry 51: 199-214.

Lahti AC, Weiler MA, Tamara Michaelidis BA, Parwani A, Tamminga CA (2001). Effects of ketamine in normal and schizophrenic volunteers. Neuropsychopharmacology 25: 455-467.

Lorrain DS, Baccei CS, Bristow LJ, Anderson JJ, Varney MA (2003). Effects of ketamine and $N$-methyl-D-aspartate on glutamate and dopamine release in the rat prefrontal cortex: modulation by a group II selective metabotropic glutamate receptor agonist LY379268. Neuroscience 117: 697-706.

Malhotra AK, Pinals DA, Adler CM, Elman I, Clifton A, Pickar D et al (1997). Ketamine-induced exacerbation of psychotic symptoms and cognitive impairment in neuroleptic-free schizophrenics. Neuropsychopharmacology 17: 141-150.

Martinez JL (1986). Memory: drugs and hormones. In: Martinez JL, Kessner RP (eds). Learning and Memory. A Biological View. Academic Press: San Diego, pp 127-163.

Moghaddam B, Adams B, Verma A, Daly D (1997). Activation of glutamatergic neurotransmission by ketamine: a novel step in the pathway from NMDA receptor blockade to dopaminergic and cognitive disruptions associated with the prefrontal cortex. J Neurosci 17: 2921-2927.

O'Dell TJ, Hawkins RD, Kandel ER, Arancio O (1991). Tests of the roles of two diffusible substances in long-term potentiation: evidence for nitric oxide as a possible early retrograde messenger. Proc Natl Acad Sci USA 88: 11285-11289.

Okaichi H, Oshima Y, Jarrard LE (1989). Scopolamine impairs both working and reference memory in rats: a replication and extinction. Pharmacol Biochem Behav 34: 599-602.

Olney JW, Labruyere J, Wang G, Wozniak DF, Price MT, Sesma MA (1991). NMDA antagonist neurotoxicity: mechanism and prevention. Science 254: 1515-1518.

Olton DS (1983). Memory functions and hippocampus. In: Seifert W (ed). Neurobiology of Hippocampus. Academic Press: New York, pp 335-369.

Palsson E, Finnerty N, Klamer D, Wass C, Svensson L, Lowry J (2009). Increased cortical nitric oxide release after phencyclidine administration. Synapse 63: 1083-1088.

Pitsikas N, Algeri S (1992). Deterioration of spatial and nonspatial reference and working memory in aged rats: protective effect of life-long calorie restriction. Neurobiol Aging 13: $369-373$.

Pitsikas N, Boultadakis A, Sakellaridis N (2008). Effects of subanesthetic doses of ketamine on rats' spatial and non-spatial recognition memory. Neuroscience 154: 454-460. 
Pitsikas N, Zisopoulou S, Sakellaridis N (2006). Nitric oxide donor molsidomine attenuates psychotomimetic effects of the NMDA receptor antagonist MK-801. J Neurosci Res 84: 299-305.

Pitsikas N, Zisopulou S, Tarantilis PA, Kanakis CD, Polissiou MG, Sakellaridis N (2007). Effects of the active constituents of Crocus sativus L., crocins, on recognition and spatial rats' memory. Behav Brain Res 183: 141-146.

Prast H, Philippu A (2001). Nitric oxide as modulator of neuronal function. Progr Neurobiol 64: 51-68.

Ramirez J, Garnica R, Boll MC, Montes S, Rios C (2004). Low concentrations of nitrite and nitrate in the cerebrospinal fluid from schizophrenic patients. Schizophr Res 68: 357-361.

Razoux F, Garcia R, Lena I (2007). Ketamine at a dose that disrupts motor behavior and latent inhibition, enhances prefrontal cortex synaptic efficacy and glutamate release in the nucleus accumbens. Neuropsychopharmacology 32: 719-727.

Rees DD, Palmer RMJ, Schulz R, Hodson HF, Moncada S (1990). Characterization of three inhibitors of endothelial nitric oxide synthase in vitro and vivo. Br J Pharmacol 101: 746-752.

Reif A, Herterich S, Strobel A, Ehlis AC, Saur D, Jacop CP et al (2006). A neuronal nitric oxide synthase (NOS-I) haplotype associated with schizophrenia modifies prefrontal cortex function. Mol Psychiatry 11: 286-300.

Roberts RC, Roche JK, Conley RR (2005). Synaptic differences in the post-mortem striatum of subjects with schizophrenia: a stereological and utrastructural analysis. Synapse 56: 185-197.
Taneli F, Piridar S, Akdeniz F, Uyanik BS, Ari Z (2004). Serum nitric oxide metabolite levels and the effect of antipsychotic therapy in schizophrenia. Arch Med Res 35: 401-405.

Tricklebank MD, Singh L, Oles RJ, Preston C, Iversen SD (1989). The behavioural effects of MK-801: a comparison with antagonists acting non-competitively and competitively at the NMDA receptor. Eur J Pharmacol 167: 127-135.

Verma A, Moghaddam B (1996). NMDA receptor antagonists impair prefrontal cortex function as assessed via spatial delayed alternation performance in rats: modulation by dopamine. J Neurosci 16: 373-379.

Wass C, Archer T, Palsson E, Fejgin K, Alexandersson A, Klamer D et al (2006a). Phencyclidine affects memory in a nitric oxidedependent manner. Working and reference memory. Behav Brain Res 174: 49-55.

Wass C, Archer T, Palsson E, Fejgin K, Klamer D, Engel JA et al (2006b). Effects of phencyclidine on spatial learning and memory: nitric oxide-dependent mechanisms. Behav Brain Res 171: 147-153.

Wesierska M, Macias-Gonzales R, Bures J (1990). Differential effects of ketamine on the reference and working memory versions of the Morris water maze task. Behav Neurosci 104: 74-83.

Yilmaz N, Herken H, Cicek HK, Celik A, Yurekli M, Akyol O (2007). Increased levels of nitric oxide, cortisol and adrenomedullin in patients with chronic schizophrenia. Med Princ Pract 16: $137-141$. 